\title{
Analisis kepuasan kerja karyawan bank penkreditan rakyat dilihat dari lingkungan kerja dan kompensasi
}

\author{
D. Agustina ${ }^{1}$, S. H. Senen \& M. Masharyono \\ Universitas Pendidikan Indonesia \\ agustina.dian@student.upi.edu
}

\begin{abstract}
The aim of the research is to find out the influence of work environment on job satisfaction, compensation on job satisfaction, and work environment and compensation on job satisfaction. The object which used as analysis unit in this research were employees of citizenry's bank X. This research used verifivicative and explanatory survey as method. Data collection techniques is using questionnaires with 25 respondents as sample. The results of this research found that the influence of work environment on job satisfaction is in the strong category, compensation that affects employee job satisfaction is in the strong category, and work environment and compensation have a strong influence on employee job satisfaction of the citizenry's bank X. However, this research found that if the condition of work environment is conducive, it will increase employee job satisfaction. On the other hand, if the implementation of compensation goes well, the employee job satisfaction will increase. Moreover, if the condition of work environment is conducive and implementation of compensation goes well, then the job satisfaction of employees citizenry's bank $X$ will increase.
\end{abstract}

Keyword: compensation; job satisfaction, work environment; bank.

Abstrak: Tujuan penelitian yaitu untuk mengetahui pengaruh lingkungan kerja terhadap kepuasan kerja, pengaruh kompensasi terhadap kepuasan kerja, serta pengaruh lingkungan kerja dan kompensasi terhadap kepuasan kerja. Objek yang menjadi unit analisis dalam penelitian ini adalah karyawan bank penkreditan rakyat $\mathrm{X}$. Jenis penelitian yang digunakan adalah verifikatif dengan metode explanatory survey. Teknik pengumpulan data yang digunakan adalah kuesioner dengan jumlah sampel 25 responden. Hasil penelitian ini menemukan bahwa pengaruh lingkungan kerja terhadap kepuasan kerja termasuk dalam kategori kuat, kompensasi berpengaruh terhadap kepuasan kerja karyawan dengan kategori kuat, serta lingkungan kerja dan kompensasi berpengaruh kuat terhadap kepuasan kerja karyawan bank penkreditan rakyat X. Dalam penelitian ini ditemukan jika kondisi lingkungan kerja kondusif, maka akan meningkatkan kepuasan kerja karyawan. Pelaksanaan kompensasi baik, maka kepuasan kerja karyawan akan meningkat. Selain itu jika kondisi lingkungan kerja kondusif dan pelaksanaan kompensasi baik, maka kepuasan kerja karyawan bank penkreditan rakyat $\mathrm{X}$ akan meningkat.

Kata Kunci: kepuasan kerja; kompensasi; lingkungan kerja; bank.

\section{PENDAHULUAN}

Sumber daya manusia harus diperhatikan dalam melaksanakan fungsi-fungsi perusahaan karena untuk memperoleh keuntungan dan menjaga eksistensi, perusahaan harus mampu meningkatkan kualitas pelayanan kepada konsumen di samping proses produksi. Permasalahan yang muncul ketika salah dalam mengelola sumber daya manusia adalah penurunan kinerja karyawan. Keberhasilan perusahaan tergantung pada bagaimana kinerja karyawan, efisiensi, kejujuran, ketekunan dan integritas (Ahmed \& Uddin, 2012). One of resources which is the most important assets organization is human resources (1), because human resources plays a role in achieving the objective organization (2). Human resources is the factor dynamic forward capable of determining or 
the withdrawal of an organization, yang menyatakan bahwa salah satu set terpenting dalam organisasi yaitu sumber daya manusia, karena sumber daya manusia berperan dalam pencapaian organisasi (Masharyono, Sumiyati, 2016).

Karyawan dalam perusahaan perlu diperhatikan karena sumber daya manusia dalam perusahaan merupakan faktor utama untuk tercapainya target produksi yang telah direncanakan. Setiap organisasi dituntut untuk selalu dapat menjaga karyawannya agar dapat menampilkan kinerja yang baik dan memelihara pegawainya agar dapat mendedikasikan diri kepada organisasi tempat di mana karywan bekerja (Masharyono, 2015), karena individu dengan harga diri rendah biasanya mengalami depresi emosional (Widjajanta, Senen, Masharyono, Lisnawati, \& Anggraeni, 2018).

Salah satu komponen terpenting yang dimiliki oleh perusahaan adalah karyawan. Perusahaan perlu mempertahankan kelangsungan hidup, mengembangkan, kemampuan bersaing dan menghasilkan laba (Senen, Sumiyati, \& Masharyono, 2017). Perhatian dibidang sumber daya manusia tidak boleh diabaikan karena hal itu merupakan aspek penting untuk merencanakan karyawan agar bekerja lebih efektif dan terus ditingkatkan dalam rangka mencapai tujuan perusahaan (Senen \& Triananda, 2016).

Sejalan dengan yang dikemukakan oleh Anas (2013) bahwa pihak perusahaan harus dapat memahami perilaku karyawannya agar kebutuhankebutuhan karyawannya dapat terpenuhi, sehingga kepuasan kerja karyawan dapat terjaga. Menurut Yulharsari (2012: 2). Kepuasan kerja dalam sebuah organisasi dibeberapa negara pada umumnya mengalami penurunan kepuasan kerja karyawannya, yang disebabkan oleh faktor ekstrinsik yaitu keadaan emosi yang dikendalikan oleh organisasi dan ketidakhadiran karyawan sehingga dapat menyebabkan ketidakpuasan dan faktor Intrinsik faktor kepuasan kerja yang bisa menjadi kekuatan motivasi, meskipun ketidakhadiran mereka tidak selalu memuaskan (Petrović et al., 2013).

Kepuasan kerja adalah kebutuhan yang selalu bertambah dari waktu ke waktu dan manusia selalu berusaha dengan segala kemampuannya untuk memuaskan kebutuhannya tersebut (Zainal et al., 2014: 856). Menurut Luthans (2014) kepuasan kerja adalah keadaan emosional yang merupakan hasil dari evaluasi pengalaman kerja seseorang. Kepuasan kerja merupakan cara mengekspresikan bagaimana seseorang merasa tentang dirinya sendiri sebagai individu dalam konteks pekerjaan mereka, yang sering berasal dari kebutuhan psikologis yang berbeda yang dialami oleh lingkungan tempat kerja (Hanna, Kee, \& Robertson, 2017).

Penelitian mengenai kepuasan kerja banyak diteliti pada sektor perbankan dan industry hotel (Aristides, Luis, Martinez José Pereira Lamelas Rosa, \& Rodrigues, 2017). Kepuasan kerja juga menjadi permasalah di bidang kesehatan, khusunya yang dialami aoleh perawat (Abualrub, El-jardali, Jamal, \& Al-rub, 2016). Salah satu perusahaan yang terindikasi mengalami permasalahan kepuasan kerja dialami juga di bank penkreditan rakyat $\mathrm{X}$. Tantangan bagi perusahaan secara umum adalah menangani ketidakpuasan karyawan dilingkungannya. Menurut Mangkunegara (2014: 50) ketidakpuasan karyawan dapat dilihat dari beberapa faktor, seperti turnover, tingkat ketidakhadiran kerja, usia, tingkat pekerjaan, dan organisasi. Data turnover pada bank penkreditan rakyat $\mathrm{X}$ dapat dilihat pada Tabel 1.

Tabel 1. Data turnover karyawan bank penkreditan rakyat $X$ tahun $2014-2017$

\begin{tabular}{llll}
\hline \multirow{2}{*}{ Tahun } & $\begin{array}{l}\text { Jumlah } \\
\text { Karyawan } \\
\text { yang Masuk }\end{array}$ & $\begin{array}{l}\text { Jumlah } \\
\text { Karyawan } \\
\text { yang Resign }\end{array}$ & $\begin{array}{l}\text { Jumlah } \\
\text { Karyawan } \\
\text { Per 31 } \\
\text { Desember }\end{array}$ \\
\hline 2014 & 1 & 0 & 26 \\
2015 & 0 & 1 & 25 \\
2016 & 1 & 0 & 26 \\
2017 & 1 & 3 & 24 \\
\hline
\end{tabular}

Sumber: SDM bank penkreditan rakyat X

Turnover merupakan perpindahan atau keluar masuknya karyawan. Perpindahan karyawan ini dapat mengganggu dalam pencapaian tujuan perusahaan. Tahun 2014 perusahaan tidak mengalami turover karyawan, tetapi pada tahun 2015 terjadi turover karyawan sebanyak 1 orang. Perusahaan mendapatkan karyawan baru sebanyak 1 orang pada tahun 2016 yang menjadikan 
karyawan kembali menjadi 26 orang. Terjadi kenaikan turnover yang cukup tinggi dibanding tahun 2015 yaitu sebanyak 3 orang, meskipun adanya karyawan baru yang masuk tetapi turnover yang terjadi lebih banyak dibanding masuknya karyawan. Winata (2015) menyatakan bahwa saat karyawan merasa tidak puas lagi terhadap pekerjaannya, maka karyawan akan cenderung memilih untuk meninggalkan pekerjaan saat itu atau absensi. Hal tersebut merupakan salah satu bentuk ketidakpuasan kerja karyawan terhadap kehidupan perusahaan. Berikut data ketidakhadiran karyawan.

Tabel 2. Persentase data absensi karyawan bank penkreditan rakyat X X tahun 2014-2017

\begin{tabular}{llllll}
\hline \multirow{2}{*}{ Tahun } & $\begin{array}{l}\text { Jumlah } \\
\text { Pegawai }\end{array}$ & $\begin{array}{l}\text { Total } \\
\text { Hari } \\
\text { Kerja }\end{array}$ & $\begin{array}{l}\text { Kehadiran } \\
\text { Kerja } \\
\text { (Hari) }\end{array}$ & $\begin{array}{l}\text { Persentase } \\
\text { Kehadiran }\end{array}$ & $\begin{array}{l}\text { Persentase } \\
\text { Ketidakhadiran }\end{array}$ \\
\hline 2014 & 25 & 254 & 245 & 96,46 & 3,93 \\
2015 & 25 & 245 & 232 & 94,69 & 5,30 \\
2016 & 26 & 243 & 226 & 93,00 & 7,00 \\
2017 & 24 & 252 & 220 & 87,30 & 12,69 \\
\hline
\end{tabular}

Sumber: SDM bank penkreditan rakyat X

Data Tabel 2 dapat dilihat bahwa terjadinya turun naik terhadap ketidakhadiran karyawan. Tingkat ketidakhadiran karyawan ini dapat dilihat dari data presentase karyawan pada tahun 2014 sampai dengan tahun 2017. Ketidakhadiran karyawan ini biasanya tanpa adanya keterangan atau biasa disebut dengan mangkir. Kemangkiran karyawan ini tentu saja dapat mengganggu dalam pencapaian tujuan perusahaan. Selain banyaknya karyawan yang mangkir, penuturan hasil wawancara dengan karyawan bagian SDM mengatakan bahwa sebagian besar karyawan sering datang terlambat. Menurut beliau keterlambatan karyawan ini berkisar antara 10-20 menit dari jam kerja yang sudah ditetapkan. Selain keterlambatan karyawan beliau juga mengatakan bahwa target perusahaan sering tidak tercapai. Bank penkreditan rakyat $\mathrm{X}$ ini setiap harinya dituntut untuk mencapai target, tetapi pada kenyataannya target tidak tercapai.

Peningkatan kepuasan kerja dapat dilakukan dengan menciptakan lingkungan kerja yang baik dan nyaman, baik lingkungan kerja fisik maupun non-fisik. Tenaga kerja yang berkualitas tinggi salah satunya didorong oleh semangat kerja yang tinggi. Dengan demikian akan berkontribusi bagi kemajuan dan kelangsungan hidup organisasi (Masharyono, 2015). Kondisi demikian akan mampu membuat karyawan merasa senang, nyaman, dan betah didalam perusahaan. Lingkungan kerja fisik yang baik dapat mengurangi tingkat kejenuhan dan tingkat stres karyawan, sehingga prestasi karyawan akan meningkat.

Menurut Greenberg dan Baron menyatakan kepuasan dapat ditingkatkan, dan perpindahan (turnover) dapat diturunkan dengan cara membuat pekerjaan menjadi menyenangkan, memberi reward untuk orang yang jujur, memberikan jenis pekerjaan yang sesuai dengan minat dan keahliannya serta menghindari kebosanan pekerjaan berulang-ulang (Winata, 2015: 517). Pimpinan perusahaan dalam membebankan tugas dan tanggung jawab kepada karyawan hendaknya juga memperhatikan lingkungan kerja karyawan. Perusahaan dituntut harus mampu memberikan rasa aman dan kenyamanan bagi karyawan dalam bekerja (Febriani \& Indrawati, 2013). Pernyataan tersebut didukung oleh hasil penelitian Febriani \& Indrawati (2013) dan Annakis, Lobo, \& Pillay (2011) menyatakan secara signifikan dan positif kepuasan kerja dipengaruhi oleh lingkungan kerja. Lingkungan kerja adalah keseluruhan sarana dan prasarana yang ada di sekitar karyawan yang sedang melakukan pekerjaan itu sendiri. Lingkungan kerja ini akan meliputi tempat kerja, fasilitas dan alat bantu kerja, kebersihan, pencahayaan dan ketenangan (Zainal et al., 2014: 168). Sedangkan menurut Wibowo (2014) lingkungan kerja secara luas mencangkup semua faktor eksternal yang mempengaruhi individu, perusahaan, dan masyarakat. Karyawan akan berkerja secara maksimal apabila lingkungan kerja nyaman dan mendukung karena pegawai merasa puas dengan lingkungan kerja yang ada (Robbins \& Judge, 2016). Sedarmayanti (2013: 26) mengungkapkan bahwa lingkungan kerja terdiri dari lingkungan kerja fisik dan lingkungan kerja non-fisik.

Selain lingkungan kerja yang dapat mempengaruhi kepuasan kerja karyawan, kompensasi pun dapat mempengaruhi kepuasan kerja. Ketidakpuasan bisa disebabkan kurangnya 
kompensasi yang diberikan perusahaan kepada karyawan. Handoko, Susanto, Prama, Hardjana, \& Lako (2004: 155) menyatakan pemberian kompensasi dapat meningkatkan kepuasan kerja karyawan. Pernyataan tersebut didukung oleh beberapa hasil penelitian yang dilakukan Igalens \& Roussel (1999) dan Rumada \& Utama (2013) menyatakan secara signifikan dan positif kepuasan kerja dipengaruhi oleh kompensasi. Tingkat kompensasi yang diberikan akan menentukan skala kehidupan ekonomi karyawan, kompensasi relatif menunjukan status dan harga karyawan. Karyawan yang memandang apabila kompensasi belum memadai maka produktivitas, prestasi, dan kepuasannya akan turun.

Kompensasi bisa dirancang secara benar untuk mencapai keberhasilan bersama sehingga karyawan merasa puas dengan jerih payah mereka dan termotivasi untuk mencapai tujuan dan sarana bersama manajemen (Kusyah, 2008: 143). Senada dengan pendapat Siagian (2007: 253) jika pegawai diliputi oleh rasa tidak puas atas kompensasi yang diterimanya dampaknya bagi organisasi akan sangat bersifat negatif artinya apabila permasalahan kompensasi tidak dapat terselesaikan dengan baik maka dapat menurunkan kepuasan kerja pegawai. Tercapainya tujuan perusahaan hanya dimungkinkan karena upaya para pelaku yang terdapat pada perusahaan tersebut (Widyanata \& Senen, 2016).

Kompensasi merupakan sesuatu yang karyawan dapatkan sebagai pengganti kontribusi jasa mereka pada perusahaan (Zainal et al., 2014: 357). Menurut Hasibuan (2013: 118) menyatakan bahwa semua pendapatan yang berbentuk uang, barang langsung atau tidak langsung yang diterima karyawan sebagai imbalan atas jasa yang diberikan kepada perusahaan. Heathfield (2012) menyatakan kompensasi merupakan jumlah uang yang dibayarkan kepada karyawan oleh perusahaan sebagai imbalan atas pekerjan yang produktif yang dilakukan. Jika karyawan tidak diberi kompensasi dengan baik, maka keadaan ketidakpuasan emosional pun akan muncul. Perbedaan emosional ini tumbuh dan terakumulasi seiring berjalannya waktu membuat karyawan mengeluh saat mereka memberikan layanan mereka kepada organisasi.
Lebih buruk lagi, indikator seperti ketidakhadiran, mangkir, lambat dan mogok dialami. Terdapat 2 dimensi yang dikemukakan oleh Zainal et al. (2014: 357), yaitu, kompensasi langsung dan kompensasi tidak langsung.

Kompensasi telah lama dianggap sebagai salah satu penghargaan organisasi yang paling penting karena memungkinkan karyawan memperoleh penghargaan lainnya (HG \& TA., 2000). Sedangkan menurut Taylor (1991) salah satu cara yang paling penting untuk memotivasi karyawan agar bekerja ekstra dan memenuhi target yang telah ditentukan perusahaan yaitu dengan kompensasi, dari kompensasi tersebut karyawan akan giat bekerja. Target perusahaan pun akan tercapai dan perusahaan akan mendapatkan keuntungan yang maksimal sesuai dengan target.

Berdasarkan latar belakang masalah diatas, maka penulis merumuskan beberapa rumusan penelitian yaitu bagaimana pengaruh lingkungan kerja terhadap kepuasan kerja karyawan di bank penkreditan rakyat $\mathrm{X}$, bagaimana pengaruh kompensasi terhadap kepuasan kerja karyawan di bank penkreditan rakyat $\mathrm{X}$, dan pengaruh lingkungan kerja dan kompensasi terhadap kepuasan kerja karyawan bank penkreditan rakyat $X$. Tujuan dari penelitian ini adalah untuk mengetahui pengaruh lingkungan kerja terhadap kepuasan kerja karyawan di bank penkreditan rakyat $\mathrm{X}$, pengaruh kompensasi terhadap kepuasan kerja karyawan di bank penkreditan rakyat $\mathrm{X}$, dan pengaruh lingkungan kerja dan kompensasi terhadap kepuasan kerja karyawan di bank penkreditan rakyat $\mathrm{X}$.

\section{METODE PENELITIAN}

Metode yang digunakan dalam penelitian ini adalah metode survey atau explanatory survey. Metode ini bertujuan untuk mengetahui pengaruh antar variabel dengan cara pengujian hipotesis. Unit analisis pada penelitian ini adalah karyawan bank penkreditan rakyat $\mathrm{X}$ pada kurun waktu kurang dari satu tahun yaitu dimulai dari bulan September 2018 sampai dengan Desember 2018, sehingga teknik pengumpulan data yang digunakan pada penelitian ini adalah cross-sectional method. Cross sectional method pengumpulan informasi 
dari setiap elemen populasi sampel yang dilakukan hanya sekali pada waktu tertentu (Sumarwan 2011: 20).

Sampel dalam penelitian ini adalah 25 orang karyawan bank pengkreditan umum dengan penarikan sampel menggunakan metode sampel jenuh, yaitu metode yang mengambil seluruh jumlah populasi. Teknik pengumpulan data yang dilakukan dalam penelitian ini melalui penyebaran kuesioner. Teknik analisis data yang digunakan dalam penelitian ini adalah analisis verifikatif. Analisis verifikatif digunakan untuk melihat pengaruh lingkungan kerja dan kompensasi terhadap kepuasan kerja (Sugiyono, 2017: 147).

Variabel dalam penelitian terdiri dari lingkungan kerja, kompensasi dan kepuasan kerja. Penelitian ini menggunakan pengukuran data berskala interval. Skala berusaha mengukur arti suatu objek atau konsep bagi responden. Skala yang digunakan dalam penelitian ini adalah skala Semantic Differential.

\section{HASIL DAN PEMBAHASAN}

Penelitian ini yang terdiri dari variabel bebas yaitu lingkungan kerja $\left(\mathrm{X}_{1}\right)$ dan kompensasi $\left(\mathrm{X}_{2}\right)$ sedangkan untuk variabel terikatnya adalah kepuasan kerja (Y). Untuk mengetahui pengaruh lingkungan kerja dan kompensasi terhadap kepuasan kerja dilakukan pengujian regresi linier berganda.

Model persamaan regresi berganda yang akan dibentuk pada penelitian ini sebagai berikut..

$$
\mathbf{Y}=\mathbf{a}+\mathbf{b}_{1} \mathbf{X}_{1}+\mathbf{b}_{2} \mathbf{X}_{2}+\mathbf{e}
$$

Sumber: Sugiyono $(2017 ; 192)$

Dimana :

$\mathrm{Y} \quad=$ Kepuasan kerja

$\mathrm{X}_{1} \quad=$ Lingkungan kerja

$\mathrm{X}_{2} \quad=$ Kompensasi

a = Bilangan konstanta

$\mathrm{b}_{1,2} \quad=$ Koefisien regresi

e = Kesalahan pengganggu (standart error)

Berdasarkan hasil pengolahan data dengan bantuan program SPSS 24.0 for windows, diperoleh koefisien regresi linear berganda sebagai berikut.

Tabel 3. Koefisien korelasi model summary

Coefficients $^{\mathrm{a}}$

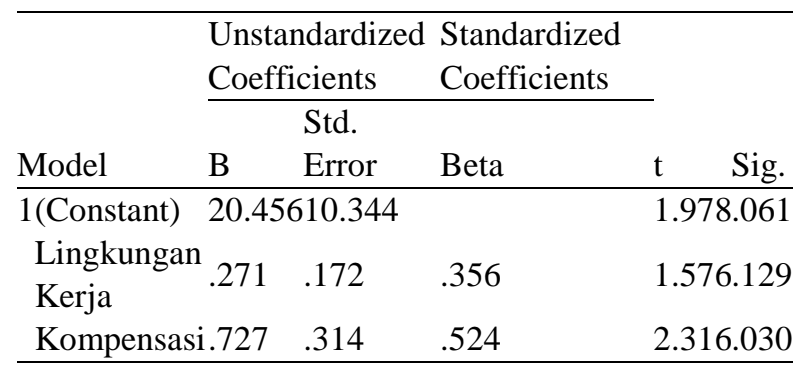

a. Dependent Variable: Kepuasan Kerja

Sumber: Hasil Pengolahan Data, 2018

Berdasarkan Tabel 3 pada kolom B, tercantum nilai konstanta dan nilai koefisien regresi linear berganda untuk variabel bebas. Berdasarkan nilainilai itu maka dapat ditentukan model regresi linear berganda yang dinyatakan dalam bentuk persamaan sebagai berikut:

$$
\begin{gathered}
\mathbf{Y}=\mathbf{a}+\mathbf{b}_{1} \mathbf{X}_{\mathbf{1}}+\mathbf{b}_{2} \mathbf{X}_{\mathbf{2}}+\mathbf{e} \\
\mathrm{Y}=20,456+0,271 \mathrm{X}_{1}+0,727 \mathrm{X}_{2}
\end{gathered}
$$

Persamaan diatas dapat diartikan sebagai berikut:

$\mathrm{a}=15,228$ : artinya jika variabel $\mathrm{X}$, bernilai nol (0), Maka variabel Y akan bernilai 15,228

$\mathrm{b}_{1}=0,617$ : artinya jika lingkungan kerja $(\mathrm{X})$ meningkat sebesar satu satuan dan variael lainnya konstan, maka variabel $\mathrm{Y}$ akan meningkat sebesar 0,617

$\mathrm{b}_{2}=0,727$ : artinya jika kompensasi $\left(\mathrm{X}_{2}\right)$ meningkat sebesar satu satuan dan variabel lainnya konstan, maka kepuasan kerja (Y) akan meningkat sebesar 0,727 satuan.

Untuk mengetahui besarnya persentase pengaruh $\mathrm{X}_{1}$ dan $\mathrm{X}_{2}$ terhadap $\mathrm{Y}$, koefisien determinasi dapat diketahui dengan rumus yang dikemukakan Riduwan (2013: 136) yaitu :

Keterangan :

$$
\mathrm{KD}=\mathbf{r}^{2} \times 100 \%
$$

$\mathrm{KD}=$ Koefisien determinasi

$\mathrm{r} \quad=$ Koefisien korelasi

$100 \%=$ Konstanta

Pengaruh lingkungan kerja terhadap kepuasan kerja dapat dilihat dari hasil Tabel 4 berikut:

Tabel 4. Koefisien Determinasi Secara Parsial

\begin{tabular}{llll}
\hline \multicolumn{2}{l}{ Model Summary } \\
\hline & $\mathrm{R}$ & Adjusted R & Std. Error of the \\
ModelR & Square & Square & Estimate \\
\hline
\end{tabular}


\begin{tabular}{llll}
\hline 1 & $.811^{\mathrm{a}} .658$ & .643 & 5.000
\end{tabular}

a. Predictors: (Constant), Lingkungan Kerja

b. Dependent Variable: Kepuasan Kerja

Sumber: Hasil Pengolahan Data, 2018

$\mathrm{KD}=\mathrm{r}^{2} \times 100 \%$

$=(0,811)^{2} \times 100 \%$

$=65,8 \%$

Maka diperoleh nilai KD sebesar 65,8\% yang menunjukkan arti bahwa lingkungan kerja memberikan pengaruh secara parsial sebesar 65,8\% terhadap kepuasan kerja. Sedangkan sisanya sebesar 35,2\% dipengaruhi oleh faktor yang tidak diteliti dipenelitian ini, seperti 1) kerja yang secara mental menantang 2) ganjaran yang pantas 3) kondisi kerja yang mendukung 4) rekan kerja yang mendukung dan 5) kesesuaian kepribadian pekerjaan (Robbins \& Judge, 2016).

Hasil tersebut sejalan dengan penelitian Ramadya, Hadi, \& Suryoko (2016) yang menyatakan bahwa lingkungan kerja berpengaruh positif dan signifikan terhadap kepuasan kerja karyawan. Penelitian mengenai pengaruh kompensasi dan lingkungan kerja terhadap kepuasan kerja yang dilakukan oleh Fauzi (2017), menyatakan hasil lingkungan kerja secara parsial berpengaruh signifikan terhadap kepuasan kerja karyawan.

Pengaruh kompensasi terhadap kepuasan kerja dapat dilihat dari hasil Tabel 5 berikut:

Tabel 5. Koefisien Determinasi Secara Parsial

\begin{tabular}{|c|c|c|c|}
\hline \multicolumn{4}{|c|}{ Model Summary ${ }^{b}$} \\
\hline ModelR & $\begin{array}{l}\mathrm{R} \\
\text { Square }\end{array}$ & $\begin{array}{l}\text { Adjusted R } \\
\text { Square }\end{array}$ & $\begin{array}{l}\text { Std. Error of the } \\
\text { Estimate }\end{array}$ \\
\hline .83 & .694 & .681 & 4.729 \\
\hline
\end{tabular}

a. Predictors: (Constant), Kompensasi

b. Dependent Variable: Kepuasan Kerja

Sumber: Hasil Pengolahan Data, 2018

$\mathrm{KD}=\mathrm{r}^{2} \times 100 \%$

$=(0,833)^{2} \times 100 \%$

$=69,4 \%$

Maka diperoleh nilai KD sebesar $69,4 \%$ yang menunjukkan arti bahwa kompensasi memberikan pengaruh secara parsial sebesar $69,4 \%$ terhadap kepuasan kerja. Sedangkan sisanya sebesar 30,6\% dipengaruhi oleh faktor yang tidak diteliti pada penelitian ini, seperti 1) kerja yang secara mental menantang 2) ganjaran yang pantas 3) kondisi kerja yang mendukung 4) rekan kerja yang mendukung dan 5) kesesuaian kepribadian pekerjaan (Robbins \& Judge, 2016).

Hal tersebut sejalan dengan penelitian terdahulu bahwa kompensasi secara parsial berpengaruh positif dan signifikan terhadap kepuasan kerja karyawan (Fauzi, 2017). Hasil penelitian Ramadya et al. (2016) menyatakan hal yang sama, bahwa kompensasi berpengaruh positif dan signifikan terhadap kepuasan kerja pada karyawan.

Adapun pengaruh lingkungan kerja dan kompensasi terhadap kepuasan kerja dapat dilihat dari hasil Tabel 6 berikut:

Tabel 6. Koefisien Determinasi Secara Simultan



Maka diperoleh nilai KD sebesar $72,5 \%$ yang menunjukkan arti bahwa lingkungan kerja dan kompensasi memberikan pengaruh secara simultan sebesar 72,5\% terhadap kepuasan kerja. Sedangkan sisanya sebesar $27,5 \%$ dipengaruhi oleh faktor yang tidak diteliti pada penelitian ini, seperti 1) kerja yang secara mental menantang 2) ganjaran yang pantas 3) kondisi kerja yang mendukung 4) rekan kerja yang mendukung dan 5) kesesuaian kepribadian pekerjaan (Robbins \& Judge, 2016).

Uji statistik $\mathrm{t}$ pada dasarnya menunjukkan seberapa jauh pengaruh satu variabel penjelas/independen secara individual dalam menerangkan variabel dependen. Untuk mengetahui besarnya persentase pengaruh lingkungan kerja dan kompensasi terhadap kepuasan kerja. Maka menggunakan program SPSS 24.0 for windows, diperoleh output sebagai berikut:

Tabel 7. Nilai Signifikan Uji t 


\begin{tabular}{|c|c|c|c|c|}
\hline \multirow[b]{2}{*}{ Model } & \multicolumn{2}{|c|}{$\begin{array}{l}\text { Unstandardized } \\
\text { Coefficients }\end{array}$} & $\begin{array}{l}\text { Standardized } \\
\text { Coefficients }\end{array}$ & \multirow[b]{2}{*}{ Sig. } \\
\hline & B & $\begin{array}{l}\text { Std. } \\
\text { Error }\end{array}$ & Beta & \\
\hline$\overline{1(\text { Constant })}$ & 15,228 & 811,011 & & 1.383 .180 \\
\hline $\begin{array}{l}\text { Lingkungan } \\
\text { Kerja }\end{array}$ & .617 & .093 & .811 & 6.655 .000 \\
\hline Kompensasi & i1.157 & .160 & .833 & 7.225 .000 \\
\hline
\end{tabular}

a. Dependent Variable: Kepuasan Kerja

Sumber: Hasil Pengolahan Data, 2018

Berdasarkan Tabel 5 perolehan thitung sebesar 6,655 untuk lingkungan kerja dan 7,225 untuk kompensasi. Tingkat signifikan $(\alpha)$ sebesar $10 \%$, dan derajat kebebasan $\mathrm{df}=\mathrm{n}-\mathrm{k}=25-3=22$ didapat nilai $t_{\text {tabel }} 1,717$.

Nilai $t_{\text {hitung }}$ lingkungan kerja sebesar 1,576. Dikarenakan $t_{\text {hitung }}>t_{\text {tabel }}$ atau 6,655> 1,717 maka $\mathrm{H}_{\mathrm{a}}$ diterima artinya lingkungan kerja berpengaruh signifikan terhadap kepuasan kerja, dengan besarnya pengaruh lingkungan kerja terhadap kepuasan kerja sebesar 0,811 atau $81,1 \%$ termasuk kedalam kategori sangat kuat (Sugiyono, 2017: 184). Hasil penelitian ini sesuai dengan teori dua faktor yang menyatakan kepuasan ataupun ketidakpuasan dapat dipengaruhi kondisi tempat bekerja, kualitas, keamanan, pengawasan kerja serta hubungan yang berlangsung dengan orang lain Wibowo (2014: 502). Selain itu, penelitian ini juga sesuai dengan teori Herzberg yaitu kepuasan kerja dipengaruhi oleh lingkungan fisik dan non fisik Ardana (2012: 22). Hasil penelitian ini didukung dengan beberapa kajian yang telah dibuktikan. Sardzoska \& Tang (2012), Annakis, Lobo, \& Pillay (2011) dan Paripurna (2013) menyatakan secara signifikan dan positif kepuasan kerja dipengaruhi oleh lingkungan kerja.

Nilai $t_{\text {hitung }}$ kompensasi sebesar 7,225. Dikarenakan $t_{\text {hitung }}>t_{\text {tabel }}$ atau 7,255 $>1,717$ maka $\mathrm{H}_{\mathrm{a}}$ diterima, artinya kompensasi berpengaruh signifikan terhadap kepuasan kerja, dengan besarnya pengaruh kompensasi terhadap kepuasan kerja sebesar 0,833 atau 83,3\% termasuk kedalam kategori sangat kuat (Sugiyono, 2017: 184). Hasil penelitian ini didukung oleh Wibowo (2014: 502) yang menyatakan kepuasan atau ketidakpuasan kerja dapat dipengaruhi dengan pengupahan. Hasil penelitian ini juga konsisten dengan kajian yang menyebutkan kepuasan kerja dipengaruhi oleh kompensasi. Igalens \& Roussel (1999), Widodo (2004), serta Rumada \& Utama (2013) menyatakan secara signifikan dan positif kepuasan kerja dipengaruhi oleh kompensasi.

Uji statistik $\mathrm{F}$ pada dasarnya menunjukkan apakah semua varibel independen atau bebas yang dimasukkan dalam model mempunyai pengaruh secara bersama-sama terhadap variabel dependen/terikat. Uji ini digunakan untuk menguji siginifikansi pengaruh lingkungan kerja dan kompensasi terhadap kepuasan kerja rumus uji $\mathrm{F}$ atau uji ANOVA dijelaskan pada tabel berikut.

Tabel 8. Nilai Signifikan Uji F

\begin{tabular}{llllll}
\hline ANOVA $^{\mathrm{a}}$ & \multicolumn{4}{c}{} \\
\hline & $\begin{array}{l}\text { Sum of } \\
\text { Model }\end{array}$ & \multicolumn{2}{c}{ Mean } \\
Squares & df Square & F & Sig. \\
\hline 1 Regression1219.778 & 2 & 609.889 & $29.028 .000^{\mathrm{b}}$ \\
Residual & 462.222 & 22 & 21.010 & & \\
Total & 1682.000 & 24 & & & \\
\hline
\end{tabular}

a. Dependent Variable: Kepuasan Kerja

b. Predictors: (Constant), Kompensasi, Lingkungan

Kerja

Sumber: Hasil Pengolahan Data, 2018

Berdasarkan Tabel 6 pengujian pengaruh variabel bebas secara bersama-sama terhadap variabel terikatnya dilakukan dengan menggunakan uji $\mathrm{F}$. Hasil perhitungan statistik menunjukan nilai $\mathrm{F}_{\text {hitung }}=29,028>\mathrm{F}_{\text {tabel }}=2,56$ $\left(\mathrm{df}_{1}=3-1=2, \mathrm{df}_{2}=25-2=23, \alpha=10 \%\right)$ dan signifikansi sebesar $0,000<0,10$. Dengan demikian dapat disimpulkan bahwa hipotesis dalam penelitian ini yaitu $\mathrm{H}_{0}$ ditolak dan $\mathrm{H}_{\mathrm{a}}$ diterima, sehingga secara bersama-sama terdapat pengaruh antara lingkungan kerja dan kompensasi terhadap kepuasan kerja di bank penkreditan rakyat X.

Hal tersebut sesuai dengan penelitian yang dilakukan oleh Ramadya, Hadi, \& Suryoko (2016) yang menyatakan bahwa lingkungan kerja dan kompensasi secara bersama-sama (simultan) berpengaruh positif dan signifikan terhadap kepuasan kerja. Sejalan dengan penelitian Fauzi (2017) yang mengemukakan bahwa kompensasi dan lingkungan kerja secara bersama-sama berpengaruh signifikan terhadap kepuasan kerja karyawan.

\section{KESIMPULAN DAN SARAN}


Hasil penelitian menyatakan bahwa, lingkungan kerja mempunyai pengaruh terhadap kepuasan kerja karyawan dengan kategori sangat kuat. Hal ini menunjukkan bahwa semakin kondusif lingkungan kerja perusahaan, maka semakin tinggi pula kepuasan kerja karyawan bank penkreditan rakyat $\mathrm{X}$. Kompensasi berpengaruh terhadap kepuasan kerja karyawan dengan kategori sangat kuat, hal tersebut menunjukkan bahwa semakin naik pelaksanaan kompensasi di perusahaan, makan akan semakin tinggi pula kepuasan kerja karyawan di bank penkreditan rakyat X. Hasil lainnya adalah lingkungan kerja dan kompensasi berpengaruh terhadap kepusan kerja karyawan dengan kategori sangat kuat. Hal tersebut menjelaskan bahwa semakin kondusif lingkungan kerja dan semakin baik pelaksanaan kompensasi, maka akan semakin tinggi kepuasan kerja yang dirasakan oleh karyawan bank penkreditan rakyat $\mathrm{X}$.

Berdasarkan hasil penelitian, maka penulis menyarankan beberapa hal yang dapat meningkatkan kepuasan kerja melalui lingkungan kerja. Perusahaan harus meningkatkan aspek lingkungan kerja fisik dengan melakukan perbaikan ataupun penambahan fasilitas dalam menunjang pekerjaan dan kesejahteraan karyawan dalam bekerja. Sedangkan untuk meningkatkan kepuasan kerja karyawan melalui kompensasi dapat dilakukan dengan cara perusahaan mengoptimalkan pemberian gaji karyawan secara langsung, misalnya dengan tepat waktu dalam pemberian gaji karyawan dan memberikan gaji lembur yang sesuai pada karyawan.

\section{DAFTAR PUSTAKA}

Abualrub, R., El-jardali, F., Jamal, D., \& Al-rub, N. A. (2016). Exploring the relationship between work environment, job satisfaction, and intent to stay of Jordanian nurses in underserved areas. Applied Nursing Research, 31, 19-23. https://doi.org/10.1016/j.apnr.2015.11.014

Ahmed, S., \& Uddin, M. N. (2012). Job Satisfaction of Bankers and its Impact in Banking: A Case Study of Janata Bank. Journal ASA University Review, $6(2)$.

Anas, K. (2013). Pengaruh Kompensasi dan Lingkungan Kerja Terhadap Kepuasan Kerja Karyawan PT. Karya Mitra Muda. Manajemen Journal.
Annakis, J., Lobo, A., \& Pillay, S. (2011a). Exploring Monitoring, Work Environment And Flexibility As Predictors Of Job Satisfaction Within Australian Call Centres. International Journal of Business and Management, 6(8), 75-93.

Annakis, J., Lobo, A., \& Pillay, S. (2011b). Exploring Monitoring, Work Environment And Flexibility As Predictors Of Job Satisfaction Within Australian Call Centres. International Journal of Business and Management, 6(8), 75-93.

Ardana, I. K. (2012). Manajemen Sumber Daya Manusia. Yogyakarta: Graha Ilmu.

Aristides, Luis, F., Martinez José Pereira Lamelas Rosa, \& Rodrigues. (2017). Mediation of Job Embeddedness and Satisfaction in the Relationship Between Task Characteristics and Turnover A Multilevel Study in Portuguese Hotels. International Journal of Contemporary Hospitality Management, 29(1), 248-267.

Fauzi. (2017). Pengaruh Kompensasi dan Lingkungan Kerja terhadap Kepuasan Kerja Karyawan PT. Tor Ganda Medan. Jurnal Riset Manajemen \& Bisnis, 2(3), 36-47.

Febriani, N. M. T., \& Indrawati, A. D. (2013). Pengaruh Motivasi, Kompensasi, serta Lingkungan Kerja Fisik Terhadap Kinerja Kerja Karyawan Hotel The Niche Bali. E-Jurnal Manajemen Universitas Udayana, 2(5).

Handoko, H., Susanto, A., Prama, G., Hardjana, A., \& Lako, A. S. (2004). Strategi Organisasi (Cetakan Pe). Yogyakarta: Amara Books.

Hanna, B., Kee, K. F., \& Robertson, B. W. (2017). Positive Impacts of Social Media at Work: Job Satisfaction, Job Calling, and Facebook Use among Co-Workers. SHS Web of Conferences, 33.

Hasibuan, M. (2013). Manajemen Sumber Daya Manusia (Tujuh Bela). Jakarta: Bumi Aksara.

Heathfield, S. M. (2012). Salary. Retrieved from http://humanresources.about.com/od/glossarys/g/sa lary.htm

HG, H., \& TA., J. (2000). Compensation in Organizations: Current Research and Practice (In Rynes S). San Fransisco: Jossey-Bass.

Igalens, J., \& Roussel, P. (1999). A Study of the Relationships between Compensation Package, Work Motivation and Job Satisfaction Author(s). Journal of Prganizational Behavior, 20(7).

Kusyah, I. R. (2008). Manajemen Sumber Daya Manusia. Yogyakarta: ANDI.

Luthans, F. (2014). Organization Behavior. New York: McGraw Hill International.

Mangkunegara, A. A. A. P. (2014). Manajemen Sumber Daya. Manusia Perusahaan. Bandung: Remaja Rosdakarya.

Masharyono. (2015). Pengaruh Job Characteristics terhadap Semangat Kerja Pegawai (Survey pada 
Pegawai PNS di Lingkungan Disparbud Jabar). Jurnal Riset Akuntansi Dan Keuangan, 3(3), 813830.

Masharyono, Sumiyati, \& Toyib. (2016). Physical Work Environment Effect on Employee Productivity of Textile Industry. Atlantis Press, 15, 630-632.

Paripurna, I. G. D. (2013). Pengaruh Kepemimpinan, Ligkungan Kerja dan Komunikasi Terhadap Kepuasan Kerja Karyawan. E-Journal Manajemen Universitas Udayana, 2(5).

Petrović, M. D., Đeri, L., Marković, J. J., Galamboš, A., Galamboš, T., \& Jovičić, A. (2013). Educational Level Differences in Job Satisfaction and Service Orientation: Case of Hotels in Novi Sad (Serbia). International Journal of Business Tourism and Applied Sciences, 1(2), 21-29.

Ramadya, W. A., Hadi, S. P., \& Suryoko, S. (2016). Pengaruh Lingkungan Kerjadan Kompensasi terhadap Kepuasan Kerja Karyawan bagian Service Departement pada PT. Astra Internasional, TbkDaihatsu Branch Office Semarang. Jurnal Ilmu Administrasi Bisnis, 5(4), 405-417. Retrieved from https://ejournal3.undip.ac.id/index.php/jiab/article/ view/13571

Riduwan. (2013). Cara Menggunakan dan Memakai Analisis Jalur (Path Analysis). Bandung: Alfabeta.

Robbins, S. P., \& Judge, T. A. (2016). Organizational Behavior (17th ed.). United States: Pearson Education.

Rumada, G., \& Utama, I. W. M. (2013a). Pengaruh Kompensasi, Kepemimpinan, dan Lingkungan Kerja Fisik Terhadap Kepuasan Kerja Karyawan Hotel Taman Harum Ubud Gianyar. E-Jurnal Manajemen Unud, 2(1), 106-120.

Rumada, G., \& Utama, I. W. M. (2013b). Pengaruh Kompensasi, Kepemimpinan, dan Lingkungan Kerja Fisik Terhadap Kepuasan Kerja Karyawan Hotel Taman Harum Ubud Gianyar. E-Jurnal Maanejemn Universitas Udayana, 2(1).

Sardzoska, E. G., \& Tang, T. L. (2012). Work-Related Behavioral Intentions in Macedonia: Coping Strategies, Work Environment, Love of Money, Job Satisfaction and Demographic Variables. Journal of Business Ethics, 108(3), 373-391.

Sedarmayanti. (2013). Manajemen Sumber Daya Manusia. Bandung: Refika Aditama.

Senen, S. H., Sumiyati, \& Masharyono. (2017). Employee Performance Assessment System Design Based on Competence. Innovation of Vacational Technology Education, 2(8), 68-70.

Senen, S. H., \& Triananda, N. (2016). The Employee Performance Influenced by Communication: a Study of BUMD in Indonesia, 15, 596-598.

Siagian, S. (2007). Fungsi-Fungsi Manajerial. Jakarta: Bumi Aksara.
Sugiyono. (2017). Metode Penelitian Kuantitatif, Kualitatif dan $R \& D$. Bandung: Alfabeta.

Sumarwan, U. et al. (2011). Riset Pemasaran dan Konsumen: Panduan Riset dan Kajian Kepuasan, Perilaku, Pembelian, Gaya Hidup, Loyalitas dan Persepsi Risiko. Bogor: IPB Press.

Taylor, F. W. (1991). The Principles Of Scientific Management.

Wibowo. (2014). Manajemen Kinerja. Jakarta: Rajawali.

Widjajanta, B., Senen, S. H., Masharyono, Lisnawati, \& Anggraeni, C. P. (2018). The impaact of Social Media Usage and Self-Esteem on Conspicuous Consumption: Intagram User of Hijabers Community Bandung Member. International Journal of eBusines and e Goverment Studies, 10(2), $1-13$.

Widodo, P. (2004). Pengaruh Lingkungan Kerja Pada Hubungan Antara Kompensasi dan Kepemimpinan Terhadap Kepuasan Kerja Studi Pada Kantor Pelayanan Pajak Salatiga. Jurnal Dayasaing, 5(2), 44-52.

Widyanata, R., \& Senen, S. H. (2016). Pengaruh Lingkungan Dan Kemampuan Kerja Terhadap Kinerja Karyawan PT . Ronadamar Sejahtera Cabang Bandung. Journal of Business Management Education, 1(2), 47-55.

Winata, A. P. (2015). Pengaruh Kepemimpinan, Komunikasi, Motivasi dan Disiplin Kerja terhadap Kinerja Karyawan Trans Jaya Ekspedisi Semarang. Jurnal Manajemen, 5(10), 1-13.

Yulharsari, F. D. (2012). Pengaruh Kepemimpinan, Kompensasi, dan Budaya Organisasi terhadap Kepuasan Kerja Karyawan. Universitas Gunadarma.

Zainal, V. R., Hadad, M. D., \& Ramly, M. (2014). Kepemimpinan dan Perilaku Organisasi. Depok: PT. RajaGrafindo Persada. 